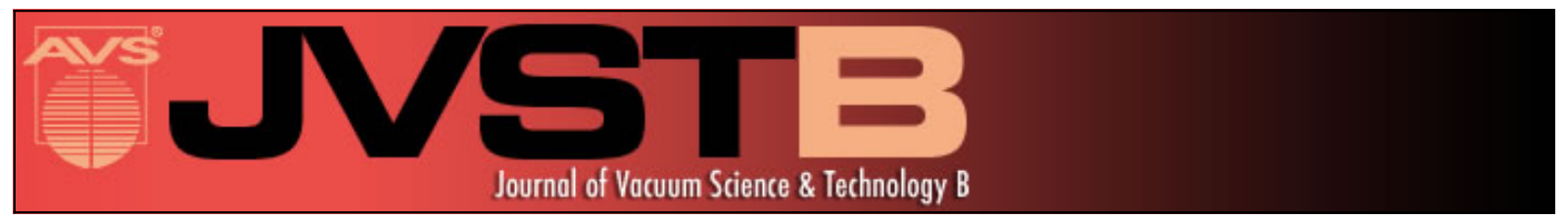

\title{
GaAs-substrate-based long-wave active materials with type-II band alignments
}

S. R. Johnson, S. Chaparro, J. Wang, N. Samal, Y. Cao, Z. B. Chen, C. Navarro, J. Xu, S. Q. Yu, David J. Smith , C.-Z. Guo, P. Dowd, W. Braun, and Y.-H. Zhang

Citation: Journal of Vacuum Science \& Technology B 19, 1501 (2001); doi: 10.1116/1.1386380

View online: http://dx.doi.org/10.1116/1.1386380

View Table of Contents: http://scitation.aip.org/content/avs/journal/jvstb/19/4?ver=pdfcov

Published by the AVS: Science \& Technology of Materials, Interfaces, and Processing

\section{Articles you may be interested in}

Highly tensile-strained, type-II, Ga $1-\mathrm{x} \ln \mathrm{x}$ As / GaSb quantum wells

Appl. Phys. Lett. 96, 062109 (2010); 10.1063/1.3303821

Molecular-beam epitaxy of phosphor-free $1.3 \mu \mathrm{m}$ InAIGaAs multiple-quantum-well lasers on InP (100)

J. Vac. Sci. Technol. B 25, 1090 (2007); 10.1116/1.2737434

Influence of radio frequency plasma cell conditions on the incorporation of nitrogen into GaAsN and GalnAsN J. Vac. Sci. Technol. B 22, 2448 (2004); 10.1116/1.1788681

Epitaxial growth of InGaAsSb/AIGaAsSb heterostructures for mid-infrared lasers based on strain engineering J. Vac. Sci. Technol. B 22, 2240 (2004); 10.1116/1.1775196

Long wavelength pseudomorphic InGaPAsSb type-I and type-II active layers grown on GaAs

J. Vac. Sci. Technol. B 18, 1545 (2000); 10.1116/1.591423

\section{SHIMADZU Powerful, Multi-functional UV-Vis-NIR and Excellence in Science FTIR Spectrophotometers}

Providing the utmost in sensitivity, accuracy and resolution for applications in materials characterization and nano research

- Photovoltaics

- Polymers

- Thin films

- Paints

- Ceramics

- DNA film structures

- Coatings

- Packaging materials

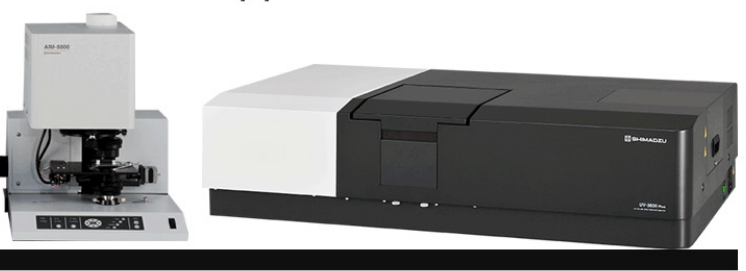




\title{
GaAs-substrate-based long-wave active materials with type-II band alignments
}

\author{
S. R. Johnson, ${ }^{\text {a) }}$ S. Chaparro, J. Wang, N. Samal, Y. Cao, Z. B. Chen, C. Navarro, \\ J. Xu, and S. Q. Yu \\ Center for Solid State Electronics Research and Department of Electrical Engineering, \\ Arizona State University, Tempe, Arizona 85287 \\ David J. Smith \\ Center for Solid State Science and Department of Physics and Astronomy, Arizona State University, \\ Tempe, Arizona 85287 \\ C.-Z. Guo, P. Dowd, W. Braun, and Y.-H. Zhang \\ Center for Solid State Electronics Research and Department of Electrical Engineering, \\ Arizona State University, Tempe, Arizona 85287
}

(Received 3 January 2001; accepted 26 May 2001)

\begin{abstract}
The optimized growth conditions and evidence for type-II alignment in GaAsSb/InGaAs heterostructures are reported. The asymmetric GaAsSb/InGaAs bilayer quantum well grown on GaAs shows promising results for device applications around the wavelength of $1.3 \mu \mathrm{m}$. Uncompensated type-II $\mathrm{GaAs} / \mathrm{GaAsSb} / \mathrm{GaAs}$ quantum-well systems and strain-compensated $\mathrm{GaAsP} / \mathrm{GaAs} / \mathrm{GaAsSb} / \mathrm{GaAs} / \mathrm{GaAsP}$ quantum-well systems are compared for $1.3 \mu \mathrm{m}$ applications. Inhomogeneous photoluminescence-linewidth broadening due to lateral composition and thickness variation is reduced from 74 to $40 \mathrm{meV}$ when GaAsP strain-compensation layers are added to GaAsSb-based trilayer quantum-well systems. () 2001 American Vacuum Society.
\end{abstract}

[DOI: $10.1116 / 1.1386380]$

\section{INTRODUCTION}

Vertical-cavity surface-emitting lasers (VCSELs) operating at $1.3-1.6 \mu \mathrm{m}$ are desirable for low-cost data transmission applications such as fiber to the home, local area networks, and free-space optical interconnects. GaAs-based 850 $\mathrm{nm}$ VCSELs are currently used for these applications but there has been interest in finding active regions that will extend the GaAs-based material system to longer wavelengths. Although these longer wavelengths have been accessible for some time using InP-substrate-based materials, InPbased $1.3 \mu \mathrm{m}$ VCSELs are difficult to realize because of the lack of materials for distributed Bragg mirrors with suitable thermal conductivity and index of refraction contrast. In order to make use of the superior optical and thermal characteristics of GaAs-substrate-based materials for 1.3-1.6 $\mu \mathrm{m}$ optoelectronic devices; we are currently developing quantum wells and double heterostructures using InGaPAsSb alloys for active regions.

One promising structure of this material system is a type-II band-aligned GaAsSb/InGaAs quantum well imbedded in GaAs. In the wavelength range of interest, the constituent materials are highly strained, which in general leads to alloy segregation and inhomogeneous broadening of the gain and photoluminescence (PL) spectra. Another possible structure is the type-II GaAsSb/GaAs multiple quantum well (QW). In this case, only the GaAsSb layers in the multilayered QW are strained, allowing the GaAsSb to be more highly strained than in the GaAsSb/InGaAs system above.

\footnotetext{
a) Author to whom correspondence should be addressed; electronic mail: shane.johnson@asu.edu
}

Because the GaAs layers do not contribute to the critical thickness, they can be thicker than InGaAs layers and they can be placed either side of the GaAsSb to form a coupled QW (CQW). CQWs are known to enhance the electron-hole wave-function overlap in electron well-hole well-electron well type-II band-alignment multilayer QWs. ${ }^{1,2}$

Strain-induced alloy segregation is strongly dependent on growth temperature. In this article, we report the optimized growth conditions and evidence for the type-II alignment of $\mathrm{GaAsSb} / \mathrm{InGaAs}$ heterostructures as well as the suitability of the GaAs/GaAsSb/GaAs QW and the GaAsP/GaAs/GaAsSb/ GaAs/GaAsP strain-compensated CQW for device applications.

\section{EXPERIMENTAL RESULTS}

The molecular-beam-epitaxy machine used for the growth was a VG V80 chamber equipped with solid-source cells. The Sb source is an all-ceramic corrosive series valved cracker manufactured by EPI containing $300 \mathrm{~g}$ of Sb that is held at a constant temperature of $550{ }^{\circ} \mathrm{C}$ in the bulk zone while the cracking zone is operated at $1000{ }^{\circ} \mathrm{C}$. An automated EPI valve controller is used to control the Sb flux, with a typical valve setting range of 40-100 depending on the $\mathrm{Sb}$ overpressure used. In the zero position the valve makes a leak tight seal to the crucible lip. For a GaSb growth rate of $15 \mathrm{~nm} / \mathrm{min}$, a valve setting of 40 gives (an absolute flux ratio) $F_{\mathrm{Sb} / \mathrm{Ga}}=1.0$ and a valve setting of 100 gives $F_{\mathrm{Sb} / \mathrm{Ga}}=3.4$. The As source is a standard EPI As valved cracker. The As bulk zone is held constant at $350^{\circ} \mathrm{C}$ while the cracker is again operated at $1000^{\circ} \mathrm{C}$. The As valve is typically operated between 70 and 120 depending on the 
overpressure desired. For a GaAs growth rate of $12 \mathrm{~nm} / \mathrm{min}$, a valve setting of 70 gives $F_{\mathrm{As} / \mathrm{Ga}}=1.0$ and a valve setting of 120 gives $F_{\mathrm{As} / \mathrm{Ga}}=2.4$.

For the absolute V/III flux ratio scale $\left(F_{\mathrm{V} / I I I}\right)$ used in this work, a ratio greater than 1.0 maintains a group-V-rich growth surface while a ratio less than 1.0 results in the accumulation of group-III droplets on the growth surface. Since these ratios, as defined, depend somewhat on the growth temperature, the following standard temperatures are used, and hence, form part of the definition: $500^{\circ} \mathrm{C}$ for $\mathrm{GaSb}$ growth and $600{ }^{\circ} \mathrm{C}$ for $\mathrm{GaAs}$ and $\mathrm{GaP}$ growth. For example, when the $\mathrm{GaSb}$ growth rate is $15 \mathrm{~nm} / \mathrm{min}$ the current reading due to the $\mathrm{Sb}_{2}$ flux (at the ion gauge used to measure source fluxes) is $1.8 \mathrm{nA}$ for $F_{\mathrm{Sb} / \mathrm{Ga}}=1.0$ and 2.5 times greater (4.5 $\mathrm{nA}$ ) for $F_{\mathrm{Sb} / \mathrm{Ga}}=2.5$. Similarly, when the GaAs growth rate is $12 \mathrm{~nm} / \mathrm{min}$ the current reading due to the $\mathrm{As}_{2}$ flux is $6.8 \mathrm{nA}$ for $F_{\mathrm{As} / \mathrm{Ga}}=1.0$ and 1.5 times greater $(10.2 \mathrm{nA})$ for $F_{\mathrm{As} / \mathrm{Ga}}$ $=1.5$. Note that the Ga flux per unit area is the same in both of these examples.

The first set of quantum-well structures consisted of an individual $7.2 \mathrm{~nm} \mathrm{In}_{x} \mathrm{Ga}_{1-x}$ As layer, an individual $7.2 \mathrm{~nm} \mathrm{GaAs}_{1-y} \mathrm{Sb}_{y}$ layer, or a combination of a $3.6 \mathrm{~nm} \mathrm{GaAs}_{1-y} \mathrm{Sb}_{y}$ layer plus a $3.6 \mathrm{~nm} \mathrm{In}_{x} \mathrm{Ga}_{1-x}$ As layer grown on (100) semi-insulating GaAs. The In mole fraction $(x)$ was approximately 0.33 , the $\mathrm{Sb}$ mole fraction $(y)$ was approximately 0.34 , and the growth temperature for each sample was $500{ }^{\circ} \mathrm{C}$. The absolute flux ratios for the growth of the GaAsSb layers were $F_{\mathrm{As} / \mathrm{Ga}}=1.5$ and $F_{\mathrm{Sb} / \mathrm{Ga}}=2.5$.

The growth of the InGaAs QWs is optimized in terms of In composition and growth temperature for the longest possible wavelength that gives strong and relatively narrow (30-40 meV) room-temperature photoluminescence spectra (using a $1 \mathrm{kA} / \mathrm{cm}^{2}$ excitation density at $514 \mathrm{~nm}$ ). The optimal In mole fraction is determined to be about 0.33 with an optimal growth temperature between 480 and $500{ }^{\circ} \mathrm{C}$. Growth temperatures lower than $480^{\circ} \mathrm{C}$ result in narrower PL linewidths due to less In segregation, but at the cost of much lower PL intensity, presumably due to the increase of material defects at the lower growth temperatures.

PL spectra from the first set of quantum-well structures are shown in Fig. 1. The PL peak location (in $\mathrm{nm}$ ) and peak width (in meV) are shown. It is evident from these data that the PL wavelength is extended via a type-II band alignment in the GaAsSb/InGaAs quantum wells. The cost of utilizing this material system is a less-intense PL spectrum from the type-II bilayer than from either of the individual materials, which is expected from our theoretical analysis. ${ }^{1}$ The $\mathrm{Sb}$ mole fraction of the GaAsSb layer is adjusted so that the type-II bilayer emits at the desired wavelength. A $0.34 \mathrm{Sb}$ mole fraction is around the point where the GaAsSb/GaAs system goes from type-I to type-II band alignment (see Fig. 3). Therefore, the electron well of the GaAsSb/GaAs layer is either very shallow or nonexistent. The electron well is shown as very shallow in the insets in Fig. 1, as well as the approximate band alignments for the type-II bilayer QW. Emission wavelengths can easily be extended to over $1.4 \mu \mathrm{m}$ using this material system.

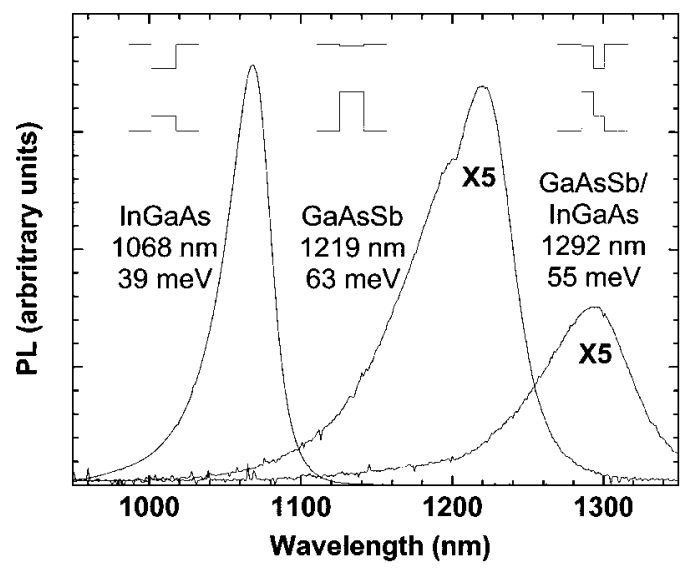

FIG. 1. Room-temperature photoluminescence (PL) spectra from a 7.2-nmthick $\mathrm{In}_{0.33} \mathrm{Ga}_{0.67} \mathrm{As}$ quantum well (QW), a 7.2-nm-thick $\mathrm{GaAs}_{0.66} \mathrm{Sb}_{0.34} \mathrm{QW}$, and a 7.2-nm-thick type-II bilayer QW consisting of $3.6 \mathrm{~nm}$ of $\mathrm{GaAs}_{0.66} \mathrm{Sb}_{0.34}$ and $3.6 \mathrm{~nm}$ of $\mathrm{In}_{0.33} \mathrm{Ga}_{0.67} \mathrm{As}$. The growth temperature was $500{ }^{\circ} \mathrm{C}$ in all cases. The As/Ga flux ratio was 1.5 and the $\mathrm{Sb} / \mathrm{Ga}$ flux ratio was 2.5 for the GaAsSb layers and the As/group-III flux ratio was 1.5 for the InGaAs layers. The band-edge cross sections are shown as insets.

A serious problem faced when growing such highly strained materials is the competition between optimal growth conditions for material quality and lateral composition and thickness variations. On one hand, the growth temperature must be high enough to obtain low-defect high-opticalquality material, while on the other, the growth temperature must be low enough to minimize the inhomogeneous broadening caused by strain-relief mechanisms such as lateral composition and layer thickness modulation.

This optimization problem occurs in both highly strained InGaAs and GaAsSb layers. In the case of highly strained $\mathrm{GaAsSb}$ on GaAs, this is further complicated by the fact that the mole fraction itself depends on growth temperature (given fixed As and $\mathrm{Sb}$ overpressures). The optimization process is illustrated in Fig. 2, where both the PL linewidth and PL intensity as a function of growth temperature are shown for a set of 7-nm-thick $\mathrm{GaAs}_{(1-x)} \mathrm{Sb}_{x}$ layers and a set of 7-nm-thick $\operatorname{In}_{x} \mathrm{Ga}_{(1-x)}$ As layers grown on GaAs. In both sets of samples mole fraction $x$ is held constant at about 0.3, giving PL emission wavelengths around $1075 \mathrm{~nm}$ for In-

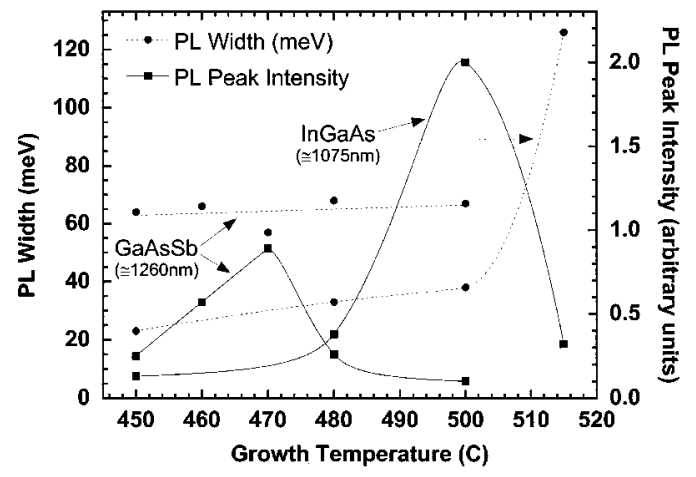

FIG. 2. Growth temperature dependence of photoluminescence linewidth and intensity for GaAsSb (PL wavelength around $1260 \mathrm{~nm}$ ) and InGaAs (PL wavelength around $1075 \mathrm{~nm}$ ). 


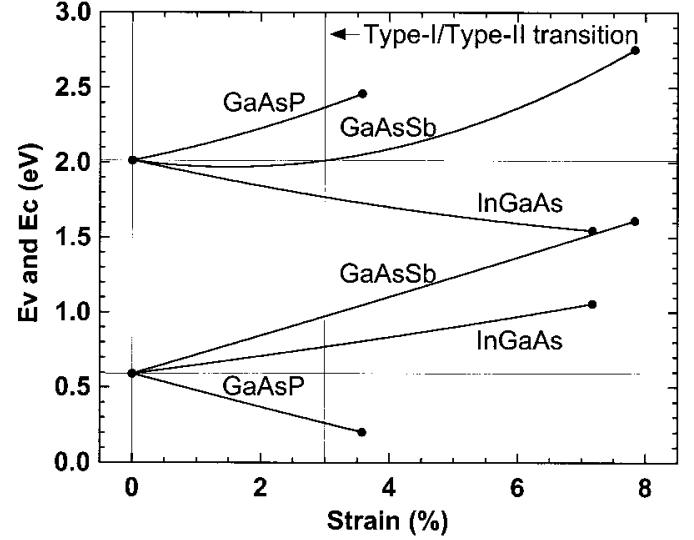

FIG. 3. Theoretical band-edge energy calculations as a function of the magnitude of strain for GaAsP, GaAsSb, and InGaAs pseudomorphic to GaAs. The conduction-band edge is given by the upper curves and the valanceband edge is given by the lower curves. The solid circles at the ends of the ternary curves are the values for each of the individual binaries.

GaAs and around $1260 \mathrm{~nm}$ for GaAsSb. Both materials exhibit an increase in inhomogeneity with growth temperature, as well as an optimal growth temperature for a maximum PL signal.

Competition between the group- $\mathrm{V}$ species for incorporation also sets the limits for suitable growth temperatures. When growing at $500{ }^{\circ} \mathrm{C}, \mathrm{As}_{2}$ is preferentially incorporated relative to $\mathrm{Sb}_{2}$, while at $450{ }^{\circ} \mathrm{C}$ the situation is reversed. At $500{ }^{\circ} \mathrm{C}$, with $F_{\mathrm{As} / \mathrm{Ga}}=1.0$ and $F_{\mathrm{Sb} / \mathrm{Ga}}=2.5$, a composition of about $\mathrm{GaAs}_{0.67} \mathrm{Sb}_{0.33}$ is achieved. Increasing the $\mathrm{Sb}$ overpressure to $F_{\mathrm{Sb} / \mathrm{Ga}}=3.5$ causes little more $\mathrm{Sb}$ to be incorporated. However, at a growth temperature of $470{ }^{\circ} \mathrm{C}$ compositions of $\mathrm{GaAs}_{0.60} \mathrm{Sb}_{0.40}$ are achieved using $F_{\mathrm{As} / \mathrm{Ga}}=1.2$ and $F_{\mathrm{Sb} / \mathrm{Ga}}$ $=1.0$. At $450{ }^{\circ} \mathrm{C}$ the same composition is achieved with the $\mathrm{Sb}$ flux reduced to $F_{\mathrm{Sb} / \mathrm{Ga}}=0.9$.

It is desirable to replace the highly strained InGaAs layer with a layer that is not strained or even tensilely strained, as both of the bilayers can be made thicker, reducing the energy shift caused by carrier confinement. (An important consideration when developing long-wave materials.) One possible choice is to replace the InGaAs layer with GaAs and increase the $\mathrm{Sb}$ content of the GaAsSb layer, exploiting the type-II band alignment between $\mathrm{GaAsSb} / \mathrm{GaAs}$ when a large $\mathrm{Sb}$ component is present. Two groups have demonstrated 1.3 $\mu \mathrm{m}$ edge-emitting lasers using this active material combination. ${ }^{3,4}$ An obvious drawback of this system is the lack of electron confinement for this active material when it is imbedded in GaAs. Other than the small amount of band bending that occurs at the $\mathrm{GaAs} / \mathrm{GaAsSb}$ and $\mathrm{GaAsSb} / \mathrm{GaAs}$ interfaces (due to the Coulomb attraction from holes confined to the GaAsSb layer), there is no electron confinement. A readily available ternary compound that offers both strain compensation and electron confinement for this system is GaAsP.

Theoretical band-edge calculations for the ternary materials discussed here are shown in Fig. 3. The band offsets have been calculated using the model-solid theory ${ }^{5}$ and the effects of strain on the band structure have been included. The upper curves in Fig. 3 show the conduction-band edge, the lower curves show the valance-band edge, and both are shown as a function of the magnitude of the strain for the case where the materials are pseudomorphic to GaAs. GaAsSb and InGaAs are compressively strained, while GaAsP is tensilely strained. These band diagrams clearly show the wide range of strain-compensated type-II QW systems available using these simple materials, namely, $\mathrm{GaAs}_{1-z} \mathrm{P}_{z}$ / $\mathrm{In}_{x} \mathrm{Ga}_{1-x} \mathrm{As} / \mathrm{GaAs}_{1-y} \mathrm{Sb}_{y} / \mathrm{In}_{x} \mathrm{Ga}_{1-x} \mathrm{As} / \mathrm{GaAs}_{1-z} \mathrm{P}_{z}$. In particular, we explore the case where $x=0$.

Doped substrates were used in the following experiments to facilitate the control of substrate temperature. The coupling between the substrate and the substrate heater thermocouple is superior for doped materials. ${ }^{6}$ The growths were done using dead reckoning under substrate heater thermocouple control with the thermocouple-substrate offset temperatures determined by pyrometry on the bare GaAs substrate before the growth was started. Run-to-run growth temperature reproducibility is very important when growing mixed group $-\mathrm{V}$ alloys because incorporation of a given group- $\mathrm{V}$ element is typically strongly temperature dependent. For the $\mathrm{GaAs}_{1-z} \mathrm{P}_{z} / \mathrm{GaAs} / \mathrm{GaAs}_{1-y} \mathrm{Sb}_{y} / \mathrm{GaAs} /$ $\mathrm{GaAs}_{1-z} \mathrm{P}_{z} \mathrm{CQW}$ system described above, where $y \approx 0.4$ and $z \approx 0.5$, the PL peak shifts about $2 \mathrm{~nm}$ toward shorter wavelengths for each $1{ }^{\circ} \mathrm{C}$ increase in growth temperature in the $470-500^{\circ} \mathrm{C}$ growth window with $F_{\mathrm{Sb} / \mathrm{Ga}}=1.0$ and $F_{\mathrm{As} / \mathrm{Ga}}$ $=1.2$.

Triple CQW systems were grown between two 40-nmthick $\mathrm{Al}_{0.2} \mathrm{Ga}_{0.8} \mathrm{As}$ barriers on $350-\mu \mathrm{m}$-thick $n^{+}$-GaAs substrates using the system described above for two cases: One with strain compensation $(z \approx 0.5)$, and one without strain compensation $(z \approx 0)$. In the samples without strain compensation, the total material thickness between the GaAsSb layers is $36 \mathrm{~nm}$ of GaAs. In the samples with strain compensation, the total layer thickness between the GaAsSb layers is $19 \mathrm{~nm}(6 \mathrm{~nm}$ of GaAs, $7 \mathrm{~nm}$ of GaAsP, and $6 \mathrm{~nm}$ of GaAs). The band-edge cross sections and PL spectra from these two

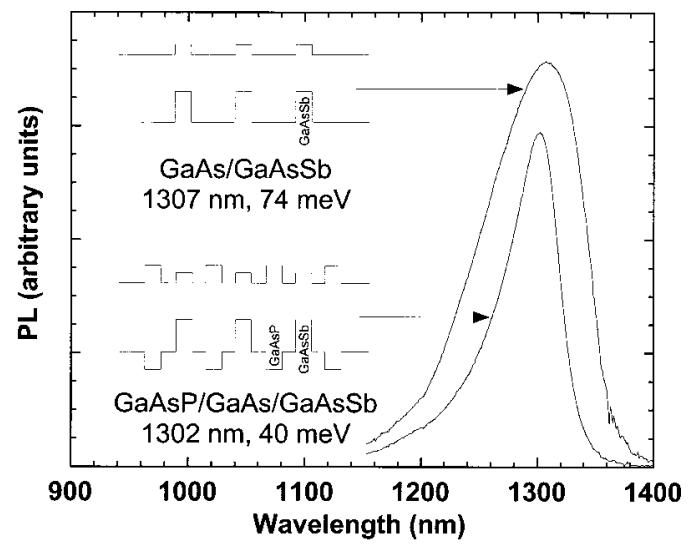

FIG. 4. Photoluminescence spectra and band-edge cross sections for triplequantum-well GaAsSb-based type-II trilayer systems. The sample without strain compensation has $36 \mathrm{~nm}$ of GaAs between each of three 7-nm-thick GaAsSb layers. The sample with strain compensation has $6 \mathrm{~nm}$ of GaAs, 7 $\mathrm{nm}$ of GaAsP, and $6 \mathrm{~nm}$ of GaAs (19 nm total) between each of three 7-nm-thick GaAsSb layers. 


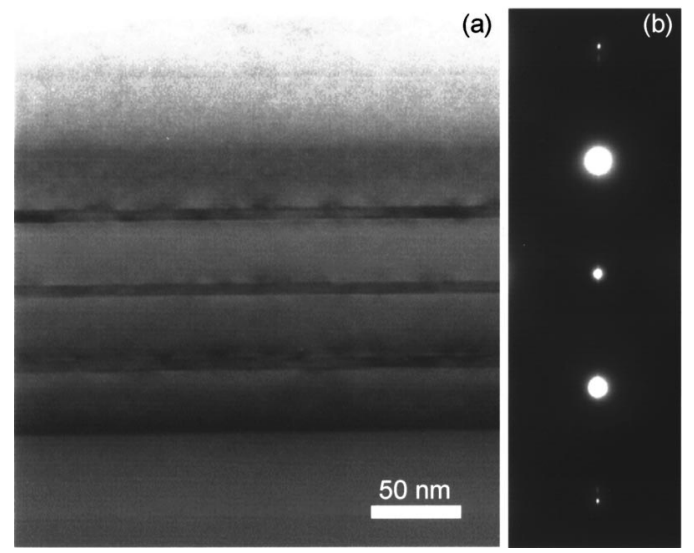

FIG. 5. (a) Cross-sectional electron micrograph showing the film microstructure of three 7-nm-thick GaAsSb layers imbedded in GaAs. Note the contrast modulations and strain contrast associated with each of the GaAsSb quantum wells. (b) Part of the [001] SAED pattern showing splitting of $\{422\}$-type spots due to pseudomorphic growth.

systems are shown in Fig. 4. The amount of material between the GaAsSb layers in the system without strain composition must be large to avoid overall relaxation of the three-CQW system.

The PL linewidth is reduced by almost a factor of 2 when strain compensation is added. There is little difference in the peak intensity from the two samples, indicating that the additional electron confinement does not necessarily enhance the oscillator strength of the CQW transition. The contribution of strain compensation to the overall structure is that it does not allow a significant amount of overall strain to accumulate as the layers are grown. This reduces inhomogeneous broadening, particularly in the third QW where lateral composition modulation without strain compensation is more evident, as shown in the transmission electron microscopy TEM cross section in Fig. 5.

Cross-sectional TEM observations permitted the microstructure of the quantum wells to be studied in more detail. Figure 5(a) shows a typical low-magnification image recorded in the [011] orientation using a small objective aper- ture which helped to emphasize contrast differences between the various layers. The growth direction is upward and the cross section consists of three 7-nm-thick GaAsSb layers imbedded in GaAs. Contrast modulations are visible in each of the GaAsSb quantum wells, suggesting the occurrence of local compositional fluctuations. Some strain contrast is also visible in the GaAs layers just above the quantum wells. Figure 5(b) shows part of a selected-area electron diffraction (SAED) pattern recorded in a [001] projection. Note the splitting of the $\{422\}$-type spots; the fainter spots, which originate from the GaAsSb quantum-well layers confirm the pseudomorphic growth. By comparing the spacing of the secondary spots from the GaAsSb layers with those of the GaAs layers, the strain of the GaAsSb layer and, hence, the $\mathrm{Sb}$ mole is inferred. The $\mathrm{Sb}$ mole fraction is estimated to be approximately 0.35 , assuming the Poisson ratio is approximately 0.3 .

\section{CONCLUSIONS}

Evidence of the type-II alignment at the heterointerface between GaAsSb and InGaAs is reported with the optimal layer configuration being the asymmetric GaAsSb/InGaAs bilayer. The suitability of GaAs/GaAsSb/GaAs and the strain-compensated $\quad \mathrm{GaAsP} / \mathrm{GaAs} / \mathrm{GaAsSb} / \mathrm{GaAs} / \mathrm{GaAsP}$ coupled-quantum-well system for long-wave applications is discussed. Inhomogeneous linewidth broadening due to lateral composition and thickness modulation is dramatically reduced by the addition of GaAsP strain-compensation layers to GaAsSb-based trilayer quantum-well systems.

${ }^{1}$ W. Braun, P. Dowd, C.-Z. Guo, S. L. Chen, C. M. Ryu, U. Koelle, S. R. Johnson, Y.-H. Zhang, J. W. Tomm, T. Elsasser, and D. J. Smith, J. Appl. Phys. 88, 3004 (2000).

${ }^{2}$ J. R. Meyer, C. A. Hoffman, F. J. Bartoli, and L. R. Ram-Mohan, Appl. Phys. Lett. 67, 757 (1996).

${ }^{3}$ M. Yamada, T. Anan, K. Tokutone, A. Kamei, K. Nishi, and S. Sugou, IEEE Photonics Technol. Lett. 12, 774 (2000).

${ }^{4}$ O. Blum and J. F. Klem, IEEE Photonics Technol. Lett. 12, 771 (2000).

${ }^{5}$ C. G. Van de Walle, Phys. Rev. B 39, 1871 (1989).

${ }^{6}$ B. V. Shanabrook, J. R. Waterman, J. L. Davis, and R. J. Wagner, Appl. Phys. Lett. 61, 2338 (1992). 